\title{
Particle swarm optimization based interval type 2 fuzzy logic control for motor rotor position control of artificial heart pump
}

\author{
Raghda Saad Raheem, Mohammed Y. Hassan, Saleem Khalefa Kadhim \\ Control and System Engineering Department, University of Technology-Iraq, Baghdad, Iraq
}

\begin{abstract}
Article Info
Article history:

Received Oct 13, 2021

Revised Dec 7, 2021

Accepted Dec 16, 2021

Keywords:

Artificial heart

Bearingless motor

Brushless DC motor

Particle swarm optimization

Type 2 fuzzy logic

ABSTRACT

Artificial heart pump (AHP) is employed to replace the native damaged heart and perform its functions. Bearingless brushless DC (BBLDC) motors are used for the implementation of the AHP. BBLDC motor is a highly nonlinear model with uncertainties and its mathematical model is hard to be found accurately. In this paper, BBLDC motor is simulated. Proportional plus integral (PI) controller is proposed to control the rotor suspension current. Furthermore, a type 2 proportional plus integral plus derivative-like fuzzy logic controller (T2 PID-Like FLC) is proposed to control the motor rotor (x, y) positions. Particle swarm optimization (PSO) technique is employed to find the best controller scaling factors and to optimize the controller inputs membership functions distribution within its universe of discourse. Simulation results showed enhancement in levitating the rotor to the required position, when using T2 PID-like FLC as compared with using type 1 PID-like fuzzy logic controller. The enhancement is measured using integral of absolute error (IAE) as a cost function to achieve $64.18 \%$ and $81.81 \%$ in the $\mathrm{x}$ and $\mathrm{y}$ axes respectively. The Performance of the motor is enhanced by $20 \%$, which decreases the rotor oscillation and increases the ability to withstand the system disturbances and nonlinearity.
\end{abstract}

This is an open access article under the CC BY-SA license.

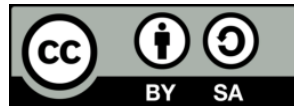

\section{Corresponding Author:}

Saleem Khalefa Kadhim

Control and systems Engineering Department, University of Technology-Iraq

Al-Sina'a St., Al-Rusafa, Baghdad, Iraq

Email: Saleem.K.Kadhim@uotechnology.edu.iq

\section{INTRODUCTION}

In recent year's miniature mechanical pumps are introduced as a ventricular assist device (VAD), for patients whose suffering from immedicable heart diseases, which introduced interesting control problems such as the speed of the motor control and rotor bearing control [1]. Magnetic bearing technology is usually used in the manufacture of VADs pumps its introduced as a solution to the problems caused by the mechanical and hydrodynamic bearings. This technology offers a great advantage by suspending the pump impeller without any connections which elements the mechanical friction and wear and it's also offers a great reliability and functionality [2].

Bearingless brushless direct ccurrent (BBLDC) motors are mostly employed for the manufacturing of the heart pumps due to its small size, high speed, and reliability. Concurrently, it has a complex mechanical system and its control system requires building speed, torque, suspension current, and rotor position controllers. In the BBLDC motors, the stator slots have two sets of windings: one for generating the electromagnetic motor torque and the other is generating the rotor suspension magnetic forces [3]. Due to this mechanical structure an interaction between two magnetic forces, the one responsible for generating the electromagnetic torque and the other for generating the suspension magnetic forces, affect the performance of the BBLDC motors and causes high nonlinearity effects. Because of the coupling effect any change of the 
load torque subjected to the motor will affect the performance of the suspension forces and causes a shift in the reference rotor position [1]. Intelligent fuzzy controllers are one of the most intelligent controllers employed to control nonlinear systems due to its ability to handle the nonlinearity and uncertainty with high efficiency. Type 2 proportional plus integral plus derivative-like fuzzy logic controller (T2 PID-Like FLC) is a generalization of a traditional type 1 proportional, integral, and derivative-like fuzzy logic controller (T1 PID-Like FLC). This suggests that uncertainty isn't just restricted to linguistic variables; it also exists in membership functions [4].

The artificial blood pump's design and control approaches have piqued experts' interest in recent years. For the pump studies, various types of motors, bearings, and controls are used. You and Yang [5] presented a nonlinear variable gain proportional plus integral plus derivative (PID) Two passively controlled radial magnetic bearings and a single axis axial artificial blood pump are controlled by this controller. They used a rotor with significant disturbances and compared the results of a regular PID controller with a nonlinear PID controller to keep the rotor levitated in the correct position. The performance is confirmed by the presence of magnetic force disturbances. Sun et al. [6] a bearingless synchronous motor was demonstrated. They introduced a neural network inverse method controller as well as two internal models of degrees of freedom. The primary purpose of this research was to achieve decoupled control of the motor speed and magnetic suspension force. A BBLDC motor with torque ripple suppression control was presented by Sun et al. [7]. A direct torque control with current prediction control was used to achieve this goal. The suspension was controlled using a PID controller. They concentrated on motor torque control to reduce the ripple caused by motor electronic commutation over a wide range of speeds. In both high and low-speed regimes, they discovered that torque ripple was much reduced. Diao et al. [8] presented an adaptive proportional plus integral (PI) speed and adaptive PI suspension controllers. An improved bacterial foraging algorithm was proposed to find controllers parameters in an online optimization process. Most of the studies used a simplified model of the real nonlinear model without considering the coupling between the two systems and the disturbances that may affect motor stability.

In this paper, a BBLDC motor bearing system control, utilized in the manufacture of an artificial heart pump, is simulated and controlled with the the aid of MATLAB/Simulink. It studies the control of the suspension forces of a blood pump impeller derived by BBLDC motor. With the presence nonlinear coupling effects between the torque forces and the suspension forces. In addition, the effect of subjecting a load torque is considered, which causes a disturbances effects on the suspension forces. Also, an initial eccentricity, of the rotor from the required position, is considered to ensure the control successes to suspend the pump impeller successfully. The purpose of this study is to offer an effective intelligent controller for the rotor suspension force in order to improve the behavior of the artificial blood pump and ensure that it can survive coupling effects and disruptions without putting the patient's life in danger. Additionally, to see if the improvement made with the proposed controller can be employed in such a delicate application.

For the suspension current a, a PI controller is employed. It basically changes the power supply current according to the rotor position in order to be stabilized in the required position. T2 PID-Like FLC is suggested to control the rotor position, since this control can deal with the system uncertainty and nonlinearity with high efficiency. A comparative study is introduced between a T1 PID-Like FLC and a T2 PID-Like FLC in controlling the motor model. For the T2 PID-Like FLC particle swarm optimization (PSO) technique is introduced to find the best controller scaling factors, the best gains of the PI current controller, and to find the best input membership functions (MFs) distribution in the universe of discourse all in the same time. For the T1 PID-Like FLC, the PSO technique is employed to find the best fuzzy logic controller scaling factors and the best PI current controller gains in the same time. An integral multiplied by the absolute value of error (IAE) is used to measure the system performance of levitating the rotor to the required position.

\section{MOTOR MATHEMATICAL MODEL}

The BBLDC motor has two sets of windings in the single stator tooth: one for the motor electromagnetic torque generation and the other for rotor levitation force generation [9]. The single tooth concentrated coils cause highly nonlinear coupling between the electromagnetic torque and suspension force generation [7]. Figure 1(a) presents the winding arrangement for BBLDC motor. A four-pole bearing is presented by a1-a2, b1-b2, and c1-c2 while the three-phase motor windings are A, B, and C. Figure 1(b) shows the suspension windings arrangement, the stator teeth in the two sides of the start are wound with the same phase windings [10]. It is required to control the currents in the two windings so that exciting phase changes every $30^{\circ}[1]$. 


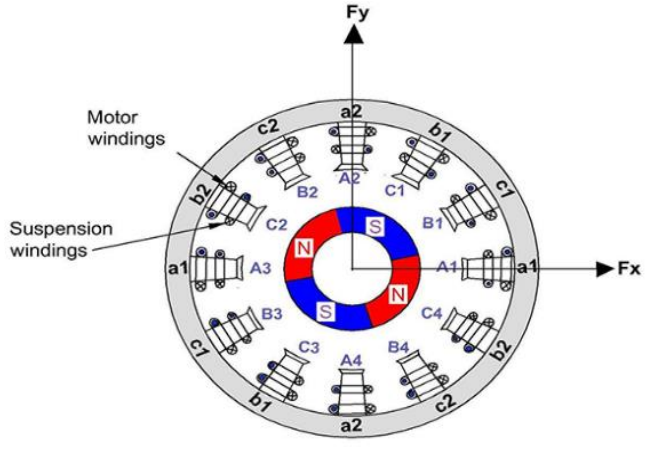

(a)

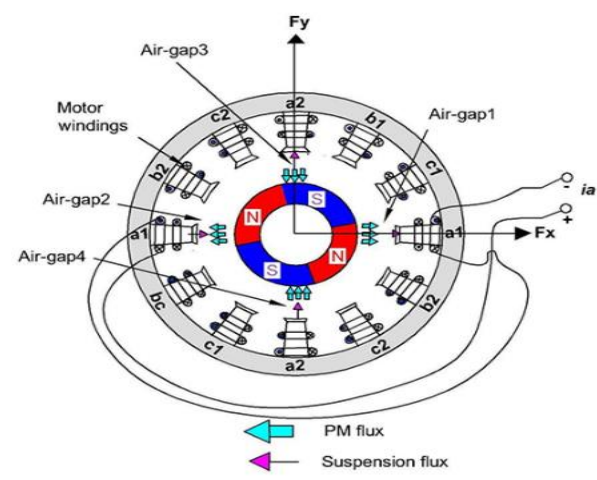

(b)

Figure 1. Winding arrangement for BBLDC motor: (a) phases distribution on the stator teeth and (b) the suspension windings arrangement on the stator teeth [9]

\subsection{Principle of electromagnetic torque generation}

The motor function is achieved when the motor windings in the stator teeth are excited. The principle of torque generation in the proposed BBLDC motor is the same as that in conventional three-phase brushless DC motor [1]. The three-phase motor's voltages and currents have a certain relationship [11]:

$$
\left|\begin{array}{l}
V_{A} \\
V_{B} \\
V_{C}
\end{array}\right|=\left|\begin{array}{ccc}
R_{S} & 0 & 0 \\
0 & R_{S} & 0 \\
0 & 0 & R_{S}
\end{array}\right|\left|\begin{array}{l}
i_{A} \\
i_{B} \\
i_{C}
\end{array}\right|+\frac{d}{d t}\left|\begin{array}{lll}
L_{A A} & L_{A B} & L_{A C} \\
L_{B A} & L_{B B} & L_{B C} \\
L_{C A} & L_{C B} & L_{C C}
\end{array}\right|\left|\begin{array}{l}
i_{A} \\
i_{B} \\
i_{C}
\end{array}\right|+\left|\begin{array}{c}
e_{A} \\
e_{B} \\
e_{C}
\end{array}\right|
$$

where $V_{A}, V_{B}$ and $V_{C}$ are the stator voltages of phases $\mathrm{A}, \mathrm{B}$, and $\mathrm{C}$ respectively, $R_{S}$ is the resistance of the torque windings, the three phases' self-inductances are $L_{A A}, L_{B B}$, the mutual inductances between them are $L_{C C}, L_{A B}, L_{A C}, L_{B A}, L_{B C}, L_{C A}$ and $L_{C B}$,; the three phases' currents are $i_{A}, i_{B}$, and $i_{C}$, are the three phases $\mathrm{B}-\mathrm{EMF}$ and the three phases is $e_{A}, e_{B}$ and $e_{C}$. The electromagnetic torque $(T)$ is calculated using the (2) [12].

$$
T=P\left(\lambda_{e} f\left(\theta_{e}\right) i_{A}+\lambda_{e} f\left(\theta_{e}-\frac{2 \pi}{3}\right) i_{B}+\lambda_{e} f\left(\theta_{e}+\frac{2 \pi}{3}\right) i_{C}\right)
$$

Where $P$ is the poles number, $\lambda_{e}$ is the flux linkage's maximum value for a permanent magnet (PM), $f\left(\theta_{e}\right)$ is the rotor position flux function, which has a trapezoidal shape. The motion equation of the system is (3) [12].

$$
T-T_{L}=J \frac{d \omega_{m}}{d t}+B \cdot \omega_{m}
$$

Where $T_{L}$ represents stands for torque applied to the load, $J$ is the rotor moment of inertia, $B$ represents the viscous friction coefficient, and $\omega_{m}$ is the motor rotational speed. The basic equations for the mathematical model of the BLDC motor can be found in (1)-(3).

\subsection{Principle of suspension force generation}

The motor and suspension currents create and manage the suspension magnetic forces required for successful rotor suspension. In the $x$ and $y$ directions, the suspension forces are represented as (4) [13].

$$
\left|\begin{array}{l}
F_{x} \\
F_{y}
\end{array}\right|=\grave{M} I_{m e}\left|\begin{array}{cc}
\cos 2\left(\theta+\frac{\varphi}{2}\right) & \sin 2\left(\theta+\frac{\varphi}{2}\right) \\
\sin 2\left(\theta+\frac{\varphi}{2}\right) & -\cos 2\left(\theta+\frac{\varphi}{2}\right)
\end{array}\right| \cdot\left|\begin{array}{c}
i_{s d} \\
i_{s q}
\end{array}\right|
$$

Where $M$ is the mutual inductance between the torque and suspension windings' derivative, $I_{m e}$ is the equivalent current for the torque winding and magnets in the ' $\mathrm{d}-\mathrm{q}$ ' rotational coordinates, $\theta$ is the motor rotational angle, $\varphi$ is the angle between the permanent magnet and the torque current positions, The q-d axes currents of the suspension windings are $i_{s d}$ and $i_{s q}$. In the 'd-q' rotational coordinates, the equivalent current for the torque winding and magnets is [14]:

$$
\begin{gathered}
\bar{I}_{m e}=I_{P}+J I_{q} \\
\varphi=\tan ^{-1} \frac{I_{q}}{I_{P}}
\end{gathered}
$$


where $I_{p}$ is the PM equivalent current and $I_{q}$ represents the torque current amplitude. The armature reaction is a coupling between the torque magnetic linkages created by winding inductance and the PM magnetic connections [14]. Also, disturbances may be present in the magnetic bearing system such as delay influence, which may represent a lag element. Another disturbance is the interference in two perpendicular axes if the angular position of the spinning magnetic fields is incorrectly assessed or detected by the controller [14].

The mechanical system of the magnetic bearing specified in the x-axis has a transfer function of (7) [13].

$$
\frac{x}{i_{x}}=\frac{K_{i x}}{m s^{2}-K_{x x}}
$$

Where $m$ is the rotor mass, $K_{i x}$ represent the force-current factor in the x-axis, and $K_{x x}$ is the forcedisplacement factors. The characteristic equation $\left(m s^{2}-K_{x x}=0\right)$ shows the absence of a first-order term in the denominator, as well as a negative term $\left(K_{x x}\right)$, indicates that the system is unstable [14].

\section{MOTOR SIMULATION AND CONTROL}

The BBLDC motor simulation and control are accomplished with the aid of MATLAB/Simulink. The BBLDC motor simulation is a complex process that requires a good knowledge of the power electronics, electrical systems, control systems, and mechanical systems [15]. Figure 2 illustrates the simulation model of the motor. It is built as two control systems (motor and bearing) with four controlling units: rotational speed control, torque current control, rotor position control, and the suspension forces currents control [16]. In this paper, the bearing system control is studied, it is controlled with two control units, the first unit is for the rotor position control and the second unit is for controlling the suspension current. Intelligent fuzzy logic controllers are employed to control the $(x, y)$ position control while a conventional PI controller is proposed for controlling the current. PWM-enabled power electronic circuits deliver the required voltages to the suspension windings, resulting in the required current for rotor position adjustment. A delay in the rate of change of current must follow the controller signal very quickly, or the rotor may strike the stator inner-surface, inflicting significant damage.

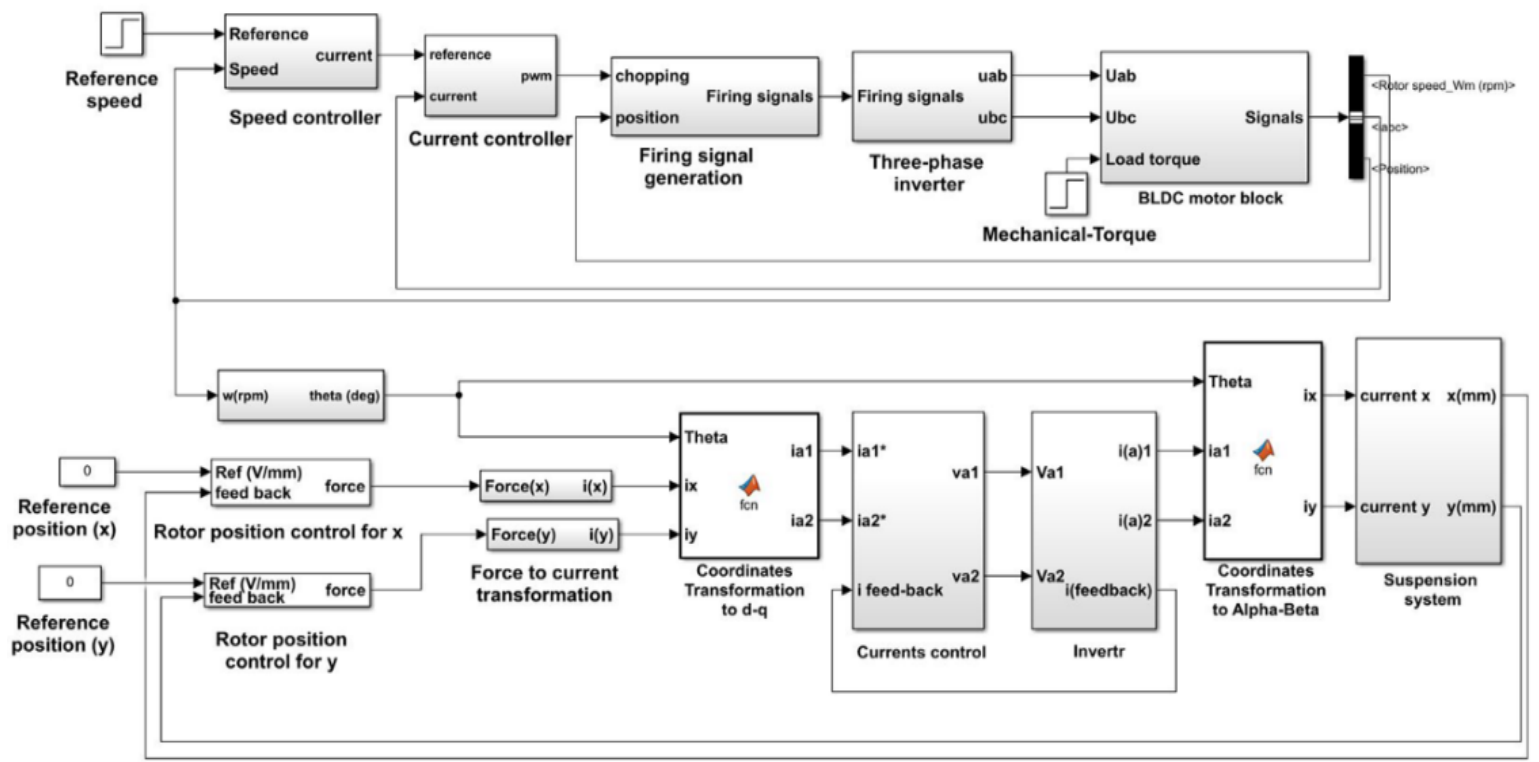

Figure 2. Simulation model of the BBLDC motor [16]

For the rotor position control, a T1 PID-Like FLC and T2 PID-Like FLC are used and compared. The suspension system block as shown in Figure 3. To levitate the rotor, the inputs are currents and suspension forces. The rotor weight, force-current factor, and force-displacement factor all influence the amount of suspension forces [17]. When constructing a suitable suspension controller, the presence of an external disturbance should be taken into account [18]. To control the rotor position in the $\mathrm{x}$ and $\mathrm{y}$ axes compared with the rotor reference position, a fuzzy controller is designed to generate the appropriate suspension forces. 


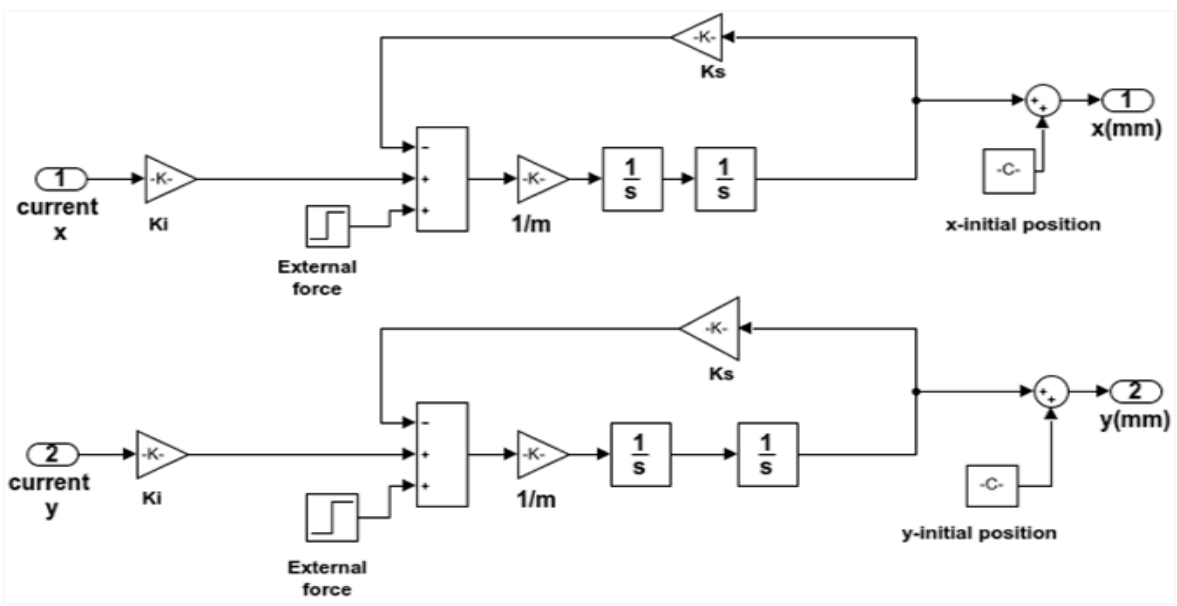

Figure 3. The BBLDC motor's suspension system [17]

\subsection{Type 1 fuzzy logic controller}

There are many known structures used in the design of the PID-like fuzzy logic controller (PID-like FLC). It may have three inputs depending on the used structure. Figure 4 shows the employed structure of the PID-like FLC. Two inputs are established, error and change of error, which make it more efficient for realtime implementation [19]. The structure is a proportional plus derivative (PD) connected to a PI like fuzzy logic controller, it is named as a PID-like FLC. For controlling the BBLDC motor with the presence of the coupling effects and disturbances, a Sugeno inference method is utilized. Figure 5 shows the membership functions (MFs) for the position error (e) and the change of error (ec) [19]. Figure 6 illustrates the two inputs MFs distribution in the universe of discourse of [-1.5 - 1.5] [19]. Figure 6 shows the output MFs distribution in the universe of discourse [19].

Negative big (NB), negative small (NS), zero (ZO), positive small (PS), and positive big (PB) are the five linguistic variables for the MFs (PB). Table 1 illustrates the fuzzy controller rules employed in the BBLDC rotor position control. The rules are chosen depending on the expected response of the system to a specific input to the system depending on past experiences of the system behavior [19]. The PSO technique is used in this case to simultaneously optimize the fuzzy controller scaling factors and the PI current controller.

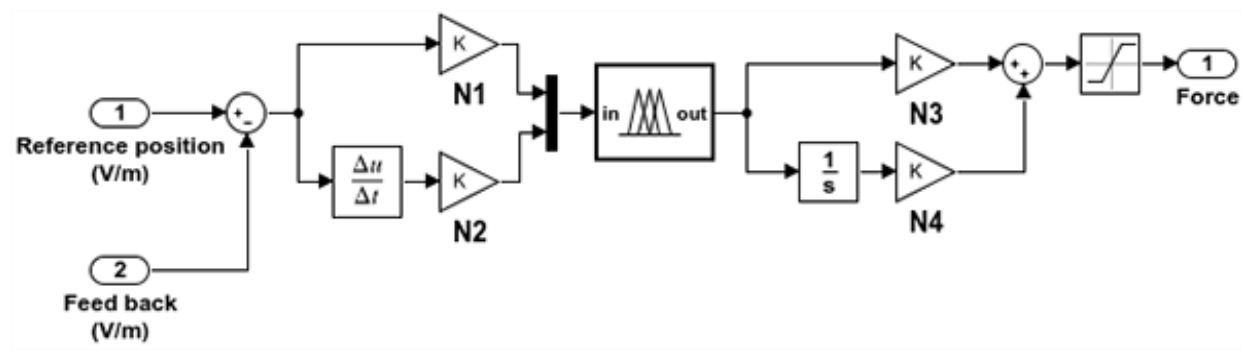

Figure 4. The PID-like FLC position controller's basic structure [19]

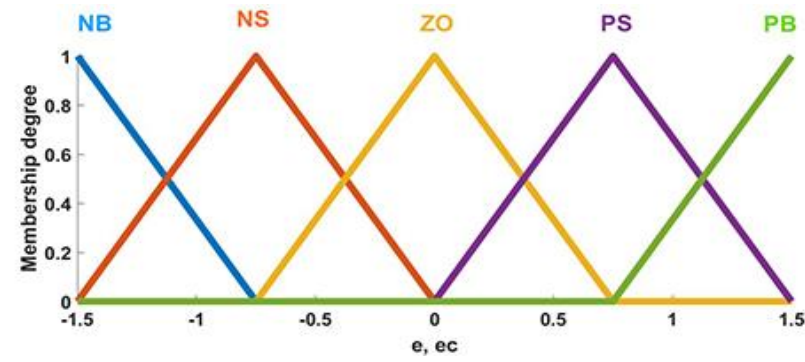

Figure 5. Membership functions for the inputs (e and ec) of the T1 PID-like FLC [19]

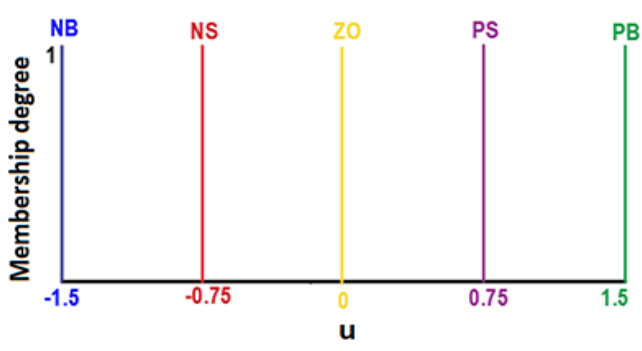

Figure 6. Membership functions for the output (u) of the T1 PID-like FLC [19] 
Table 1. T1 PID-like FLC rules [19]

\begin{tabular}{llllll}
\hline ec & NB & NS & ZO & PS & PB \\
\hline NB & NB & NB & NB & NS & ZO \\
NS & NB & NB & NS & ZO & PS \\
ZO & NB & NS & ZO & PS & PM \\
PS & NS & ZO & PS & PB & PB \\
PB & ZO & PS & PB & PB & PB \\
\hline
\end{tabular}

\subsection{Type 2 fuzzy logic controller}

The type 2 fuzzy logic controller, which is a generalization of the type 1 fuzzy logic controller, uses membership functions to cope with system unceratinity in three dimensions. The uncertainty in type 2 fuzzy controllers is not confined to the linguistic variables, but also extends to the membership functions. It successfully deals with the difficult-to-determine nonlinearities. It is divided into two types: the first generalizes type 2 and the second, known as interval type 2, is a simplification of the first [20].

For the BBLDC rotor position control, an interval T2 PID-like FLC is suggested, with a PID structure similar to that shown in Figure 4, with two inputs, the error (e) and change of error (ec), and a single output (u). Four scaling factors (M1, M2, M3, and M4) need to be optimized to ensure the best controller performance. A Sugeno interval type 2 (IT2) fuzzy system is suggested. The product T-norm is used to calculate the firing levels, and the enhanced Karnik-Mendal (EKM) algorithm is used to discover the crisp output using the center of sets type reduction plus defuzzification approach. For each input, three T2 MFs are recommended: two Trapezoidal shoulder MFs and one interior Triangular MF. Within the range of [1.5-1.5] is the universe of conversation [19]. For the MFs, three linguistic variables are used: negative (Nv), zero (Zo), and positive ( $\mathrm{Pv})$. The T2 PID-Like FLC rule base is listed in Table 2 [21]. When compared to a T1 PID-Like FLC, a T2 PID-Like FLC can be built with fewer MFs and rules, lowering the computational cost [22]. Different parameters can be tuned to provide the greatest performance for the T2 PID-Like FLC. Optimizing the endpoints of the higher MFs (NU, ZOU, and PU) and the lower MFs (NL, ZOL, and PL) and their distribution in the universe of discourse is one of these parameters [23]. Figure 7 shows three MFs, to perform the optimization process for the MFs ends points. These points, $\overline{\mathrm{x}}_{1}, \overline{\mathrm{x}}_{7}$, and $\overline{\mathrm{x}}_{13}$, are kept constants during the optimization process representing the limits and the center of the distribution range [4]. In this scenario, the PSO technique is used to simultaneously optimize the MF endpoints, fuzzy controller scaling factors, and PI current controller.

Table 2. T2 PID-Like FLC rules

\begin{tabular}{cccc} 
& & & \\
$\mathrm{ZO}$ & $\mathrm{Nv}$ & $\mathrm{Nv}$ & $\mathrm{ZO}$ \\
$\mathrm{Pv}$ & $\mathrm{No}$ & $\mathrm{ZO}$ & $\mathrm{Pv}$ \\
& $\mathrm{PV}$ & $\mathrm{Pv}$ \\
\hline
\end{tabular}

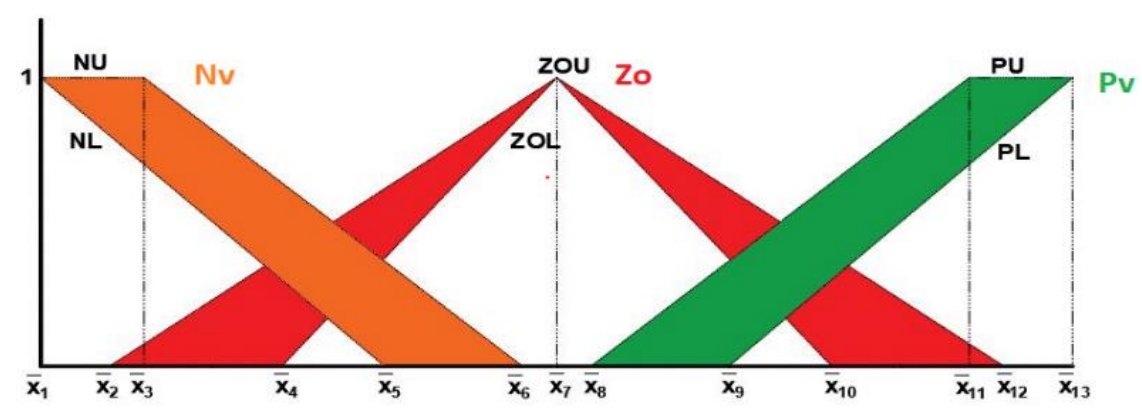

Figure 7. Distribution of the T2 PID-Like FLC membership functions for each input

\subsection{Particle swarm optimization (PSO) technique}

Several optimization techniques may be employed to optimize the performance of a specific system. PSO is one of the most popular optimization techniques. It simulates birds flock (swarm) when it searches for food. Each bird (particle) has a specific position, weight, and speed, and move around a specific search 
space [24]. The particle's movement depends on its own best-known position and the entire swarm best-known position. They are updated continuously until it reaches optimal performance. In (8) and (9) represent the mathematical representation for the updated particle speed and velocity respectively [25]:

$$
\begin{aligned}
& \mathrm{v}_{\mathrm{t}+1}=\mathrm{w} \cdot \mathrm{v}_{\mathrm{t}}+\mathrm{c}_{1} \cdot\left(\mathrm{p}_{\text {best }}-\mathrm{x}_{\mathrm{i}}\right)+c_{2} \cdot\left(\mathrm{G}_{\text {best }}-\mathrm{x}_{\mathrm{i}}\right) \\
& \mathrm{x}_{\mathrm{i}+1}=\mathrm{x}_{\mathrm{i}}+\mathrm{v}_{\mathrm{t}+1}
\end{aligned}
$$

where $v_{t+1}, x_{t+1}$ are the updated values for the particle's velocity and position, respectively, $v_{t}, x_{t}$ are the current values of velocity and location, respectively, $w$ is the weighting gain, $c_{1}, c_{2}$ are the learning factors, $\mathrm{p}_{\text {best }}$ are the best parameters values, and $\mathrm{G}_{\text {best }}$ is the best-optimized value.

The enhancement in the performances depends on optimizing a specific function known as the cost function. Because the error values evaluated by the cost function are typically quite small, a performance requirement is used in the system's design to determine the controller's efficiency [25]. These criteria come in a variety of forms. The type of response the system should provide determines which criteria to use. For the BBLDC motor optimizing, an integral of the absolute value of the error (IAE) is employed, since it doesn't add weight to the error [26].

\section{SIMULATION RESULTS}

The employed BBLDC motor has two sets of windings in the single stator tooth, with four permanent magnets mounted in the impeller surface. The impeller works as the motor rotor. Hall-effect sensors are employed to measure the radial position of the rotor and the position shifting from the rotor position Table 3 lists the BBLDC motor parameters used in the simulation [27]. Type 1 and type 2 fuzzy controllers are suggested to control the rotor position system with similar operating conditions. Coupling effects between motor and bearing functions are considered depending on (4)-(6). Two types of disturbances are presented in the simulation process; delay influence and interference effect between two perpendicular axes. The rotor is assumed to have an eccentricity from the required position of $-0.4 \mathrm{~mm}$ and $-0.6 \mathrm{~mm}$ in the $\mathrm{x}$ and y axis respectively. The speed of the rotor is fixed to $7000 \mathrm{rpm}$ and a load torque of $51 \mathrm{mN} . \mathrm{m}$ is subjected at $0.4 \mathrm{sec}$. Since coupling effects are considered, this load torque will cause a disorder in the rotor position. The rotor reference position is set to $(0,0)$ in the $\mathrm{x}$ and $\mathrm{y}$ axes. The fuzzy controllers must be able to tolerate the system's high nonlinearity and disturbance effects while elevating the rotor to the necessary position without hitting the stator inner surface. The cost function for the PSO technique is set up to incorporate the IAE estimated from position responses as well as the IAE calculated from current answers [25]:

$$
\left.F_{\text {motor }}=l * \int_{0}^{\infty}\left|e_{x}\right| d t+n * \int_{0}^{\infty}\left|e_{y}\right| d t\right)+f * F_{\text {crnts }}
$$

where $l, n$, and $f$ are weighting factors that have been chosen as positive values with the following condition: $l+n+f=1, e_{x}$ is the error measured by the $x$-axis suspension controller, while $e_{y}$ is the error measured by the $y$-axis suspension controller, and $F_{\text {crnts }}$ is the current PSO technique's cost function, and it's used to select the optimal variables out of 13 parameters. The PSO parameters used to discover the best controllers' parameters are listed in Table 4. Table 5 also shows the optimal input MF parameter values, which specify the distribution of MFs in the universe of discourse. Figure 8 shows the optimized MFs used in the control of a BBLDC motor's rotor suspension when a T2 PID-Like FLC is used to control the rotor.

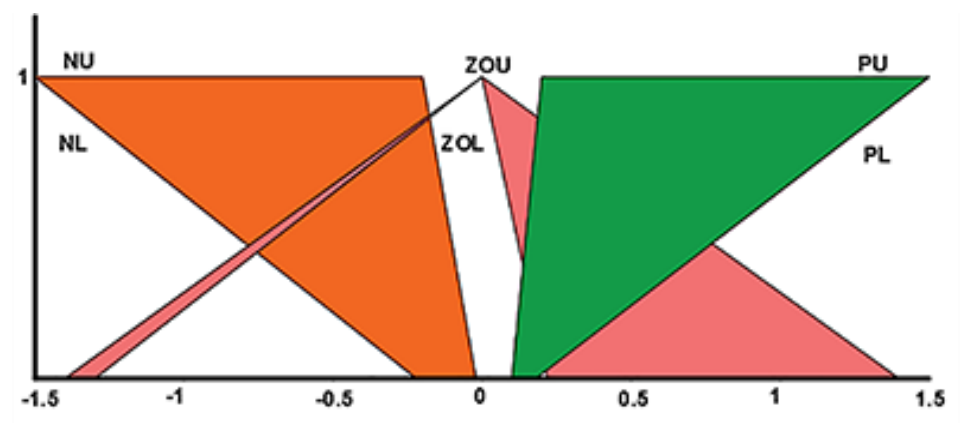

Figure 8. Optimized MF distribution, for the T2 PID-Like FLC inputs MF 
Table 3. Parameters of the blood pump [27]

\begin{tabular}{lc}
\hline \multicolumn{1}{c}{ Quantity } & Value \\
\hline Axial length of the rotor & $12.5 \mathrm{~mm}$ \\
Axial length of the PM & $7 \mathrm{~mm}$ \\
Thickness of the PM & $3 \mathrm{~mm}$ \\
Outer diameter of the rotor & $28 \mathrm{~mm}$ \\
Outer diameter of the stator & $70 \mathrm{~mm}$ \\
Air gap length & $0.75 \mathrm{~mm}$ \\
Back-electro motive force constant & $0.0147 \mathrm{~V} . \mathrm{sec} / \mathrm{rad}$ \\
Hall sensors sensitivity & $5 \mathrm{mV} / \mathrm{Gauss}$ \\
No. of suspension force windings & 80 \\
No. of torque windings & 40 \\
Remnant flux density & $1.38 \mathrm{~T}$ \\
Average torque & $38 \mathrm{mN} . \mathrm{m}$ \\
No-load speed & $24000 \mathrm{rpm}$ \\
\hline
\end{tabular}

Table 4. PSO parameters

\begin{tabular}{cc}
\hline PSO parameter & Value \\
\hline maximum iteration & 100 \\
No. of particles & 30 \\
No. of variables & 13 \\
$c_{1}$ & 1.5 \\
$c_{2}$ & 1.5 \\
Inertia & $0.5+($ rand $/ 2)$ \\
\hline
\end{tabular}

Table 5. T2 PID-Like FLC MF parameters

\begin{tabular}{cc}
\hline Point & Value \\
\hline$\overline{\mathrm{x}}_{1}$ & -1.5 \\
$\overline{\mathrm{x}}_{2}$ & -1.35 \\
$\overline{\mathrm{x}}_{3}$ & -1.2 \\
$\overline{\mathrm{x}}_{4}$ & -0.8 \\
$\overline{\mathrm{x}}_{5}$ & -0.5 \\
$\overline{\mathrm{x}}_{6}$ & -1.35 \\
$\overline{\mathrm{x}}_{7}$ & 0 \\
$\overline{\mathrm{x}}_{8}$ & 0.1 \\
$\overline{\mathrm{x}}_{9}$ & 0.5 \\
$\overline{\mathrm{x}}_{10}$ & 0.8 \\
$\overline{\mathrm{x}}_{11}$ & 1.2 \\
$\overline{\mathrm{x}}_{12}$ & 1.35 \\
$\overline{\mathrm{x}}_{13}$ & 1.5 \\
\hline
\end{tabular}

The best gains of the PI current controller $\left(\mathrm{K}_{\mathrm{psc}}\right.$ and $\left.\mathrm{K}_{\mathrm{isc}}\right)$ and T2 PID-Like FLC for position control are listed in Table 6, (M1, M2, M3, M4). In (11) is used to discover the ideal values for six parameters: the T1 PID-Like FLC gains (N1, N2, N3, and N4) and the PI current controller gains $\left(K_{p s c}\right.$ and $\left.K_{i s c}\right)$ for managing the rotor position using a T1 PID-Like FLC. Tables 7 and 8 show the PSO settings used and the controller's highest improvements discovered using the PSO technique, respectively. Figures 9 and 10 show the cost function variation for finding the best controllers parameters for the T2 PID-Like FLC and the T1 PID-Like FLC respectively.

Table 6. Position control with the best gains of the PI current controller and T2 PID-Like FLC

\begin{tabular}{cc}
\hline Gains & Best value \\
\hline M1 & 2.81 \\
M2 & 0.092 \\
M3 & 6.808 \\
M4 & 293.76 \\
$\mathrm{~K}_{\text {psc }}$ & 22.923 \\
$\mathrm{~K}_{\text {isc }}$ & 237.608 \\
\hline
\end{tabular}

Table 7. Parameters of PSO were utilized to select the optimum controllers

\begin{tabular}{|c|c|}
\hline PSO parameter & Value \\
\hline maximum iteration & 30 \\
\hline No. of particles & 25 \\
\hline No. of variables & 6 \\
\hline$c_{1}$ & 1.5 \\
\hline$c_{2}$ & 1.5 \\
\hline Inertia & $0.5+(\mathrm{rand} / 2)$ \\
\hline
\end{tabular}

Table 8. Position control with the best gains of the PI current controller and T1 PID-Like FLC

\begin{tabular}{cc}
\hline Gains & Best value \\
\hline $\mathrm{N} 1$ & 0.480 \\
$\mathrm{~N} 2$ & $4.33 \times 10^{-4}$ \\
$\mathrm{~N} 3$ & 29.95 \\
$\mathrm{~N} 4$ & 87.15 \\
$\mathrm{~K}_{\mathrm{psc}}$ & 191.80 \\
$\mathrm{~K}_{\text {isc }}$ & 38.29 \\
\hline
\end{tabular}




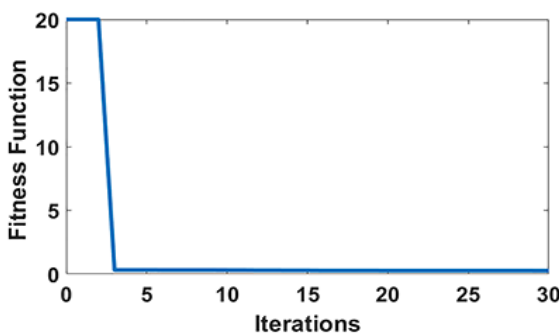

Figure 9. Obtaining the optimal T2 PID-Like FLC MFs distribution and controllers' parameters, use the cost function of variation

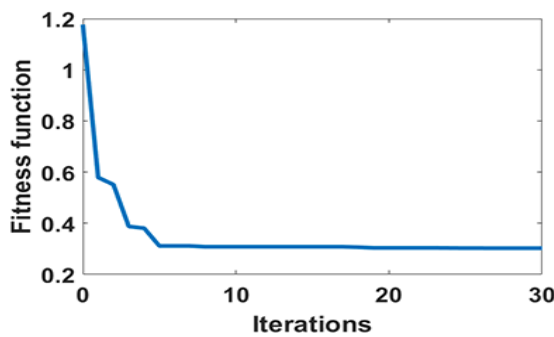

Figure 10. Variation of the PSO technique's cost function for determining the optimal position $\mathrm{T} 1$ PID-like FLC parameters

The responses of the fuzzy controller for levitating the rotor in the $\mathrm{x}$ and $\mathrm{y}$ axes are shown in Figures 11(a) and (b), respectively. When a load torque of $51 \mathrm{mN} . \mathrm{m}$ is applied, it can be seen that the position responses are affected by the load torque change. Table 9 shows the parameters of the position responses under the T2 PID-Like FLC and the T1 PID-Like FLC. When comparing the performance of the fuzzy controllers, the T2 PID-Like FLC achieves a significant improvement.

Unlike the T1 PID-Like FLC, it is able to levitate the rotor to the appropriate position. With a deviation from the desired position, the T1 PID-Like FLC stabilizes the rotor. As a result, the percentage improvement of most metrics may be greater than 100 percent. Nonetheless, until it reaches the necessary location, the response oscillates. In addition, it took longer to settle than the T1 PID-Like FLC controller. With the IAE criteria, the error criteria are improved by $64.18 \%$ and $81.81 \%$ in the $\mathrm{x}$ and $\mathrm{y}$ axes, respectively. The performance of the magnetic bearing as determined by the IAE criteria has been improved by $20 \%$.

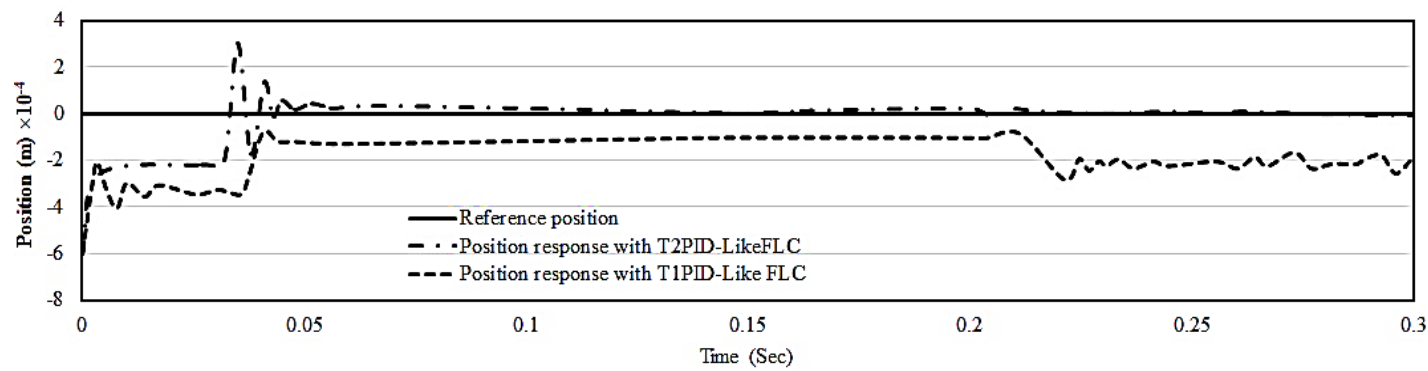

(a)

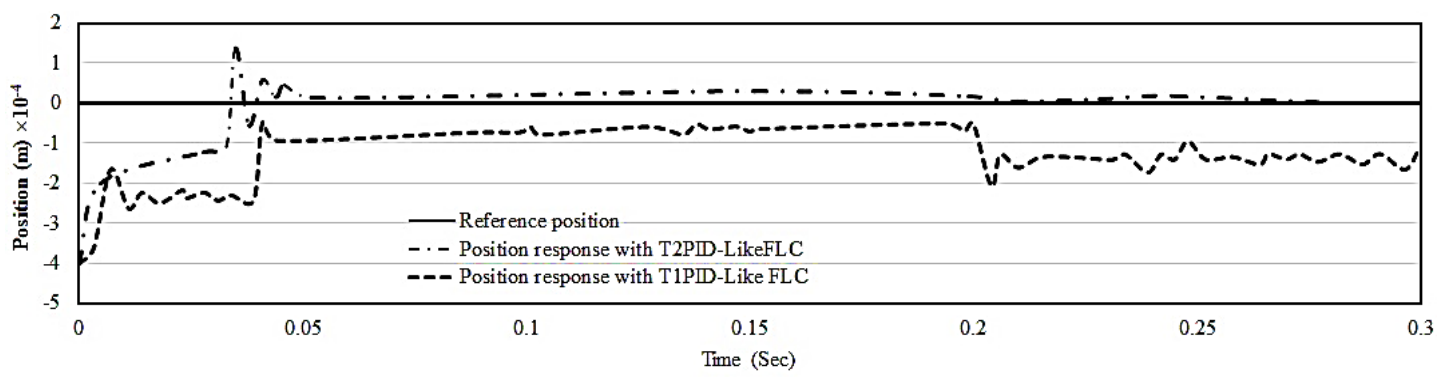

(b)

Figure 11. Position response with T2 PID-Like FLC and T1 PID-Like FLC in the (a) $x$ axis and (b) y axis

Table 9. Parameters of the position responses under the T2 PID-Like FLC and T1 PID-Like FLC

\begin{tabular}{ccccccc}
\hline Axis & IAE & $\begin{array}{c}\text { Settling time } \\
(\mathrm{sec})\end{array}$ & $\begin{array}{c}\text { Steady State position } \\
(\mathrm{mm})\end{array}$ & $\begin{array}{c}\text { Maximum position } \\
\text { drifting }(\mathrm{mm})\end{array}$ & $\begin{array}{c}\text { Max. Overshoot } \\
(\mathrm{mm})\end{array}$ & $\begin{array}{c}\text { Min. Undershoot } \\
(\mathrm{mm})\end{array}$ \\
\hline \multicolumn{2}{c}{ T2 PID-Like FLC } & & & & & \\
x & 0.067 & 0.055 & 0 & 0 & 0.3 & 0.2 \\
y & 0.044 & 0.037 & 0 & 0 & 0.13 & 0.08 \\
T1 PID-Like FLC & & & & & \\
x & 0.11 & 0.037 & -0.03 & -0.08 & - & 0.17 \\
y & 0.08 & 0.037 & -0.02 & -0.06 & - & 0.13 \\
\hline
\end{tabular}




\section{CONCLUSION}

A BBLDC motor is presented in this paper to drive an artificial blood pump. The BBLDC motor combines the motor and magnetic bearing functions. The BBLDC bearing system is inherently unstable, necessitating the use of a feedback controller to maintain stability, and the magnetic bearing's mathematical model is highly nonlinear. For magnetic rotor position control, T1 PID-Like FLC and T2 PID-Like FLC are presented. For the suspension current, a PI suspension current controller is used to test the bearing performance. The PSO technique is used to identify the best controller scaling factors for both controllers. For the T2 PID-Like FLC the distribution of the input MFs in the universe of discourse are also optimized using PSO technique. An IAE is used to measure the system performance of levitating the rotor to the required position.

The simulated results verified the effectiveness of the proposed T2 PID-Like FLC as compared to the T1 PID-Like FLC to enhance the performance of the BBLDC motor. When the performance of the two controllers is compared, the fuzzy T2PID-Like FLC achieves a substantial improvement. It is possible to lift the rotor to the desired position. The enhancements in the error calculated using IAE criteria were $64.18 \%$ and $81.81 \%$ in the $\mathrm{x}$ and $\mathrm{y}$ axes respectively. The performance of the magnetic bearing is enhanced by $20 \%$.

When considering the unknown operating conditions, T2 PID-Like FLC delivers the best results. Despite all of the disordering conditions, it is able to keep the rotor in the required position, giving it the upper hand over the type 1 PID-Like FLC. This has a significant impact on the design of artificial heart pumps. It can successfully levitate the rotor and endure disturbances by suspending the rotor in the proper position despite all of the chaotic operating conditions. As a result, a tiny motor with great reliability and efficiency can be designed. This has a significant impact on the design of artificial heart pumps. It allows for rapid changes in the amount of blood pumped to meet the needs of the patient.

\section{REFERENCES}

[1] M. Ooshima and C. Takeuchi, "Magnetic suspension performance of a bearingless brushless DC motor for small liquid pumps," IEEE Transactions on Industry Applications, vol. 47, no. 1, pp. 72-78, Nov. 2009, doi: 10.1109/TIA.2010.2091233.

[2] A. J. Humaidi, S. K. Kadhim, and A. S. Gataa, "Development of a novel optimal backstepping control algorithm of magnetic impeller-bearing system for artificial heart ventricle pump," Cybernetics and Systems, vol. 51, no. 4, pp. 1-21, May 2020, doi: 10.1080/01969722.2020.1758467.

[3] M. Ooshima, "Analyses of rotational torque and suspension force in a permanent magnet synchronous bearingless motor with short-pitch winding," In 2007 IEEE Power Engineering Society General Meeting, IEEE, Jun. 2007, pp. 1-7, doi: 10.1109/PES.2007.386135.

[4] J. M. Mendel, "Uncertain rule-based fuzzy systems.: introduction and new directions," Upper Saddle River, NJ: Prentice-Hall, 2017.

[5] Z. Q. You and S. M. Yang, "Nonlinear control of a magnetically levitated single-axis controlled axial blood pump," In 201 IEEE 2nd International Future Energy Electronics Conference (IFEEC), IEEE, Nov. 2015, pp. 1-6, doi: 10.1109/IFEEC.2015.7361460.

[6] X. Sun, Z. Shi, L. Chen, and Z. Yang, "Internal model control for a bearingless permanent magnet synchronous motor based on inverse system method," IEEE Transactions on Energy Conversion, vol. 31, no. 4, pp. 1539-1548, 2016, doi: 10.1109/TEC.2016.2591925.

[7] Y. Sun, K. Zhang, Y. Yuan, and F. Yang, "Torque ripple suppression control of bearingless brushless DC motor in wide speed regulation range," Progress In Electromagnetics Research, vol. 84, pp. 87-101, 2018, doi: 10.2528/PIERC1803210.

[8] X. Diao, H. Zhu, and D. Zhang, "Speed and displacement control system of bearingless brushless DC motor based on improved bacterial foraging algorithm," In MATEC Web of Conferences, 2016, doi: 10.1051/matecconf/20167507005.

[9] M. Ooshima and Y. Kumakura, "Stabilized Suspension Control Considering Armature Reaction in a D-Q Axis Current Control Bearingless Motor," In 2014 International Power Electronics Conference (IPEC-Hiroshima 2014-ECCE ASIA), IEEE, May 2014, pp. 1715-1720, doi: 10.1109/IPEC.2014.6869814.

[10] Y. C. Liu, H. Q. Zhu, and L. D. Zhu, "Suspension Force Control System Design and Simulation for Bearingless Brushless DC Motor," In Applied Mechanics and Materials, vol. 703, pp. 250-253, M2015, doi: 10.4028/www.scientific.net/AMM.703.250.

[11] M. Islam, "Design and Analysis of Field Oriented Control of Permanent Magnet Brushless DC Motor," Doctoral dissertation, Khulna University of Engineering \& Technology (KUET), Khulna, Bangladesh, 2017.

[12] T. Muthamizhan, P. Saravanan, and R. Maharana, "Sensorless Control of Z Source Inverter fed BLDC Motor Drive by FOC DTC Hybrid Control Strategy Using Fuzzy Logic Controller," 2021 7th International Conference on Electrical Energy Systems (ICEES), 2021, pp. 358-363, doi: 10.1109/ICEES51510.2021.9383752.

[13] B. Yue, Y. Yuan, and T. Tao, "Direct Suspension Control Based on Second Order Sliding Mode for Bearingless Brushless DC Motor," Progress In Electromagnetics Research, vol. 98, pp. 17-30, 2020, doi: 10.2528/PIERC19091602.

[14] A. Chiba, T. Fukao, O. Ichikawa, M. Ooshima, M. Takemoto, and D. G. Dorrell, "Magnetic Bearings and Bearingless Drives," Elsevier, Oxford, UK, 2005.

[15] F Zürcher, T. Nussbaumer, S. Walter, C. Wegmüller, and J. W. Kolar, "Comparison of Different Control Concepts for Bearingless Brushless Motors," 12 Symposium on Magnetic Bearings, 2010. [Online]. Available: https://www.pespublications.ee.ethz.ch/uploads/tx_ethpublications/Zuercher_ISMB12_2010_Paper.pdf

[16] Y. Sun, F. Yang, Y. Yuan, Y. Huang, "Control of Out-Rotor Bearingless Brushless DC Motor," 2017 32nd Youth Academic Annual Conference of Chinese Association of Automation (YAC), IEEE, 2017, doi: 10.1109/YAC.2017.7967485.

[17] H. P. Nguyen, X. B. Nguyen, T. T. Bui, S. Ueno, and Q. D. Nguyen, "Analysis and Control of Slotless Self-Bearing Motor," Actuators, vol. 8. no. 3. Multidisciplinary Digital Publishing Institute, 2019, doi: 10.3390/act8030057.

[18] E. H. Maslen and S.Gerhard, eds. "Magnetic Bearings: Theory, Design, and Application to Rotating Machinery," Berlin, Heidelberg: Springer-Verlag Berlin Heidelberg, 2009. 
[19] A. Noshadi, J. Shi, W. S. Lee, P. Shi, and A. Kalam, "Optimal PID-Type fuzzy logic controller for a multi-input multi-output active magnetic bearing system," Neural computing and applications, vol. 27, no. 7, pp. 2031-2046, 2016, doi: 10.1007/s00521015-1996-7.

[20] H. M. Yousif and K. Ganesh, "Interval Type-2 fuzzy position control of electro-hydraulic actuated robotic excavator," International Journal of Mining Science and Technology, vol. 22, no. 3, pp. 437-445, May 2012, doi: 10.1016/j.ijmst.2011.12.004

[21] D. Wu, "A Brief Tutorial on Interval Type-2 Fuzzy Sets and Systems," Fuzzy sets and systems, Jul. 2010.

[22] D. Wu, "Approaches for reducing the computational cost of interval type-2 fuzzy logic systems: overview and comparisons," IEEE Transactions on Fuzzy Systems, vol. 21, no.1, pp. 80-99, May 2012, doi: 10.1109/TFUZZ.2012.2201728.

[23] P. C. Shill, "Fuzzy Logic Controllers: Optimization Issues on Design and Rule Base Reduction Algorithms," A Dissertation Submitted to the University of Fukui, 2013. [Online]. Available: https://core.ac.uk/download/pdf/59042449.pdf

[24] R. Praven, "Control of an Active Magnetic Bearing System Using Pso-Based Tuning Pid Controller," Doctoral dissertation, University of Malaya, 2017

[25] A. P. Laturkar, S. Bhavani, and D. P. Adhyapak, "Random PSO \& MDBPSO based Sensor Deployment in WSN," Indonesian Journal of Electrical Engineering and Computer Science, vol. 10, no. 1, pp. 286-294, Apr. 2018, doi: 10.11591/ijeecs.v10.i1.pp286-294.

[26] Y. Zhang, F. Qiao, J. Lu, L. Wang, and Q. Wu, "Performance Criteria Research on PSO-PID Control Systems," In 2010 International Conference on Intelligent Computing and Cognitive Informatics, IEEE, 2010, pp. 316-320, doi: 10.1109/ICICCI.2010.51.

[27] H. S. Zad, T. I. Khan, and I. Lazoglu, "Design And Analysis of a Novel Bearingless Motor for a Miniature Axial Flow Blood Pump," IEEE Transactions on Industrial Electronics, vol. 65, no. 5, pp. 4006-16, Oct. 2017, doi: 10.1109/TIE.2017.2762626.

\section{BIOGRAPHIES OF AUTHORS}
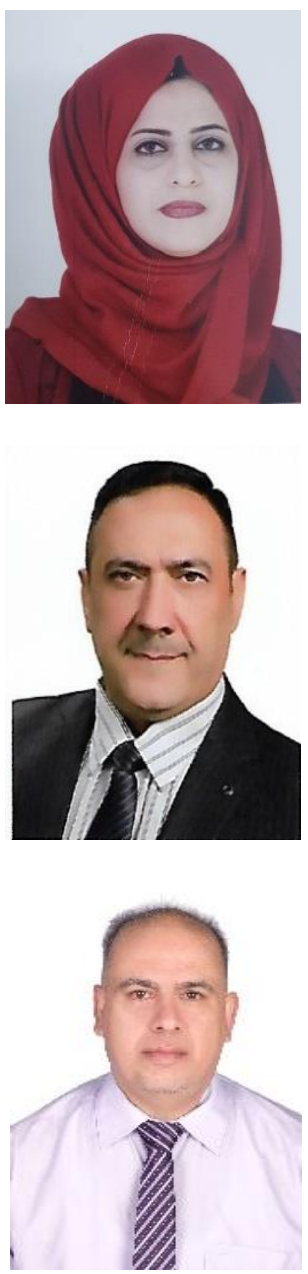

Raghda Saad Raheem (iD BI SC P received her BSc in Control and Systems Engineering from University of Technology, Baghdad, Iraq in 2012. Her research interests include artificial heart pump, Fuzzy logic control. She can be contacted at email: rsa997@yahoo.com.
Mohammed Y. Hassan (D) 8. SC P received his Ph. D. in Control and Automation Engineering at University of Technology, Iraq in 2003. He has been a Professor working with Control and Systems Engineering Department at University of Technology, Iraq since 2004. He received the B.Sc. degree in Electrical and Electronics Engineering from Al-Rasheed College of Engineering, Iraq in 1989 and the M. Sc. degree in Control Engineering from the same college 1995. His research interests include Adaptive Control, Intelligent Control Systems, Robotics, and Microcontrollers. Dr. Hassan is a member in Iraqi Academics Syndicate and in Iraqi Engineers Union. He can be contacted at email: mohammed.y.hassan@uotechnology.edu.iq.

Saleem Khalefa Kadhim (iD 8 SC P received his BSc and MSc in Mechanical Engineering from University of Technology, Baghdad, Iraq in 2000 and 2002, respectively. He is an Assistance Professor of Control and System Engineering Department at University of Technology-Iraq, Baghdad, Iraq. He obtained his PhD in Biomechanical Engineering from the Universiti Teknologi PETRONAS, Malaysia in 2017. His research interests include artificial heart pump, artificial heart valve, Adaptive Backstepping control, sliding mode control, Fuzzy logic, CFD simulation, flow induced vibration, and heat transfer. He can be contacted at email: saleem.k.kadhim@uotechnology.edu.iq. 